\title{
BMJ Open Prioritising patients for bariatric surgery: building public preferences from a discrete choice experiment into public policy
}

\author{
Jennifer A Whitty, ${ }^{1}$ Julie Ratcliffe, ${ }^{2}$ Elizabeth Kendall, ${ }^{3}$ Paul Burton, ${ }^{4}$ \\ Andrew Wilson, ${ }^{5}$ Peter Littlejohns, ${ }^{6}$ Paul Harris, ${ }^{7}$ Rachael Krinks, ${ }^{3}$ \\ Paul A Scuffham 8
}

To cite: Whitty JA,

Ratcliffe J, Kendall E, et al. Prioritising patients for bariatric surgery: building public preferences from a discrete choice experiment into public policy. BMJ Open 2015;5:e008919. doi:10.1136/bmjopen-2015008919

- Prepublication history and additional material is available. To view please visit the journal (http://dx.doi.org/ 10.1136/bmjopen-2015008919).

Received 29 May 2015 Revised 16 August 2015 Accepted 21 September 2015

CrossMark

For numbered affiliations see end of article.

Correspondence to Dr Jennifer A Whitty; j.whitty@uq.edu.au

\section{ABSTRACT}

Objectives: To derive priority weights for access to bariatric surgery for obese adults, from the perspective of the public.

Setting: Australian public hospital system.

Participants: Adults ( $N=1994)$, reflecting the age and gender distribution of Queensland and South Australia.

Primary and secondary outcome measures: $A$ discrete choice experiment in which respondents indicated which of two individuals with different characteristics should be prioritised for surgery in repeated hypothetical choices. Potential surgery recipients were described by seven key characteristics or attributes: body mass index (BMI), presence of comorbid conditions, age, family history, commitment to lifestyle change, time on the surgical wait list and chance of maintaining weight loss following surgery. A multinomial logit model was used to evaluate preferences and derive priority weights (primary analysis), with a latent class model used to explore respondent characteristics that were associated with variation in preference across the sample (see online supplementary analysis).

Results: A preference was observed to prioritise individuals who demonstrated a strong commitment to maintaining a healthy lifestyle as well as individuals categorised with very severe (BMl $\left.\geq 50 \mathrm{~kg} / \mathrm{m}^{2}\right)$ or (to a lesser extent) severe $\left(\mathrm{BMl} \geq 40 \mathrm{~kg} / \mathrm{m}^{2}\right)$ obesity, those who already have obesity-related comorbidity, with a family history of obesity, with a greater chance of maintaining weight loss or who had spent a longer time on the wait list. Lifestyle commitment was considered to be more than twice as important as any other criterion. There was little tendency to prioritise according to the age of the recipient. Respondent preferences were dependent on their BMI, previous experience with weight management surgery, current health state and education level.

Conclusions: This study extends our understanding of the publics' preferences for priority setting to the context of bariatric surgery, and derives priority weights that could be used to assist bodies responsible for commissioning bariatric services.

\section{Strengths and limitations of this study}

- This study uses a robust methodology grounded in welfare choice theories to derive weights that could be used to prioritise patients for bariatric surgery, from the perspective of the general public.

- This study represents the preferences of a large sample of adults, representative of the general population in Australia by age and gender.

- The sample was recruited from a research panel in Australia, which may limit generalisability of the findings.

\section{INTRODUCTION}

Obesity is a substantial public health problem with increasing prevalence in most countries. Bariatric surgery is recognised as a cost-effective intervention for the management of adult obesity, leading to sustained weight loss and remission from obesity-related conditions (most notably, type II diabetes mellitus). ${ }^{1-5}$ Guidelines recommend bariatric surgery be considered after non-surgical interventions have failed for those with a body mass index (BMI) greater than $40 \mathrm{~kg} / \mathrm{m}^{2}$, or greater than $35 \mathrm{~kg} / \mathrm{m}^{2}$ with comorbid conditions. ${ }^{4}{ }^{6}$ Waiting lists for bariatric surgery are growing fast and outstripping the availability of the procedure in many high-income countries. The capacity of health systems, especially publicly funded systems, to expand service provision is limited in terms of budgetary allocation and the required medical expertise. In this limited resource setting, criteria are inevitably required to prioritise access.

There is also increasing evidence that the distribution of bariatric surgery is not associated with need. For example, in Australia, access is extremely limited in the public 
hospital system, with only $7 \%$ of bariatric surgeries performed in public hospitals. ${ }^{7}$ Perversely but perhaps unsurprisingly, the lowest rates of access are reported in lower socioeconomic groups who have the highest obesity prevalence and would be likely to benefit most. ${ }^{8}$ Provision of bariatric surgery varies across the six Australian States ${ }^{3} 7$ and anecdotally has resulted in a lack of access in some areas, with long waiting lists where access is limited. Given the socioeconomic inequality, and its demonstrated cost-effectiveness for the treatment of obesity, there is pressure to expand the provision of bariatric surgery services in public hospitals. ${ }^{3}$

Public opinion is widely acknowledged as an important consideration in priority setting, ${ }^{9-12}$ and several models of public participation are available to guide engagement approaches. ${ }^{13-17}$ A clear consensus on how public opinion should be incorporated in healthcare decision-making and the impact of its inclusion is lacking. ${ }^{10}{ }^{18-20}$ Nevertheless, normative ethical (eg, procedural justice), ${ }^{21}$ economic ${ }^{22-24}$ and political (eg, deliberative democracy ${ }^{25}$ arguments provide strong support for the consideration of public preferences alongside other clinical and economic evidence when developing prioritisation criteria. Rationales for public engagement in priority-setting include promoting public confidence in the health system, increasing the transparency, accountability and legitimacy of rationing decisions and improving the responsiveness of the health system. ${ }^{9} 21 \quad 2627$ Moreover, considering public preferences is likely to be of particular importance when policy decisions allocate priorities across population groups or incorporate social value judgements, as may be anticipated in the case of obesity. ${ }^{25}{ }^{28-30}$ In the context of priority-setting for public resource allocation, it has been argued that it is the preferences of the general public rather than any subgroup who benefit that should be considered. The public as a whole fund the health system through taxation and pay any opportunity cost associated with funding a particular intervention. Moreover, using the 'average' preference of a representative sample of the general public avoids any self-interest that might be associated with decision-making. ${ }^{24} 31$

Consequently, this preference study aimed to assess the relative importance of potential criteria and tradeoffs the public would make when prioritising access to bariatric surgery for obese adults in Australia, and to use these preferences to develop 'priority weights' that could be assigned to criteria to prioritise access to bariatric surgery for adults.

\section{METHODS}

This paper presents a substudy of a larger project aiming to investigate methods for engaging the public in healthcare decision-making. ${ }^{32} 33$ A discrete choice experiment (DCE) was used to measure preferences and derive importance for different criteria that might be used to prioritise bariatric surgery for individuals. The DCE is a stated preference method that has gained popularity as an approach to eliciting preferences in health, ${ }^{34-37}$ including for setting priorities. ${ }^{38}$ In the context of priority setting, it allows the derivation of "priority weights' for different criteria on a common interval scale, and quantification of the trade-offs people would be willing to make between different criteria.

\section{DCE survey instrument}

The DCE was undertaken according to best practice guidelines. ${ }^{39}$ In the DCE, respondents were asked to make $19(18+1$ repeat choice; explained below) hypothetical choices between two different patients who would both benefit from surgical management for their obesity. Potential surgery recipients were described according to seven different characteristics or attributes which were chosen to represent possible prioritisation criteria (table 1). These attributes and the description of their levels were developed using a two stage process. First, a literature review was undertaken to indicate generic criteria of potential importance to the public in priority setting. ${ }^{38}$ Second, the initial generic criteria were refined in consultation with research partners and an expert focus group to include potential conditionspecific criteria to prioritise obese patients for bariatric surgery.

The levels of the attributes varied between the hypothetical patients in the choice sets according to a systematic $\mathrm{D}_{\mathrm{p}}$-efficient design, utilising prior coefficient values obtained from a pilot study. This approach maximised the statistical efficiency of the design while ensuring that all main effects and selected two-way interaction effects could be estimated independently. ${ }^{40}$ The final design consisted of 162 different choice sets (example choice set in figure 1), which were divided into 9 blocks of 18 choice sets. A 10th D-efficient block of 18 choice sets was also used to allow comparison of the data to other samples who completed this block only, for purposes related to the wider project which are beyond the scope of the current paper. ${ }^{32}$ Thus, there were 10 survey versions, each consisting of 18 different choice sets. One choice set was reversed and repeated as a 19th choice set in each version as an indicator for internal choice consistency; responses to the 19th repeat choice set were excluded from the DCE analysis (as this was a duplicate choice set and not part of the experimental design). Respondents were randomised to one of the 10 survey versions.

Extensive pilot testing was undertaken to confirm the face validity of the instrument, prior to main data collection. This involved face-to-face completion of the survey by an adult convenience sample $(n=20)$, with qualitative exploration of understanding of the instrument along with estimation of a preliminary choice model. The final survey (see online supplementary material) presented some background information on obesity, an explanation of the choice task, followed by the 19 choice sets. 
Table 1 Attributes and levels

\begin{tabular}{|c|c|}
\hline Attribute & Level \\
\hline Current level of obesity & $\begin{array}{l}\text { Obesity (BMI } 30 \text { to less than } 40 \mathrm{~kg} / \mathrm{m}^{2} \text { ) } \\
\text { - Severe obesity (BMI } 40 \text { to less than } 50 \mathrm{~kg} / \mathrm{m}^{2} \text { ) } \\
\text { - Very severe obesity (BMI greater than } 50 \mathrm{~kg} / \mathrm{m}^{2} \text { ) }\end{array}$ \\
\hline Obesity-related conditions & $\begin{array}{l}\text { Already has obesity-related conditions } \\
\text { Is at risk of developing obesity-related conditions }\end{array}$ \\
\hline Age of person needing surgery & $\begin{array}{l}20 \text { years } \\
-35 \text { years } \\
-50 \text { years }\end{array}$ \\
\hline Family history & $\begin{array}{l}\text { At least one parent or sibling is obese, has had weight issues } \\
\text { since childhood } \\
\text { No family history of obesity }\end{array}$ \\
\hline $\begin{array}{l}\text { Chance of maintaining a substantial (at least half) } \\
\text { reduction in excess weight }\end{array}$ & $\begin{array}{l}30 \% \\
70 \% \\
-70 \%\end{array}$ \\
\hline $\begin{array}{l}\text { Has shown commitment by responding to prescribed } \\
\text { lifestyle intervention (ie, physical activity and diet) }\end{array}$ & $\begin{array}{l}\text { Has maintained a healthy lifestyle plan for several months, } \\
\text { resulting in some weight loss, however is still in need of surgery } \\
\text { Has not maintained a healthy lifestyle plan and has had no } \\
\text { weight loss }\end{array}$ \\
\hline Time already spent on surgery waiting list & $\begin{array}{l}-6 \text { months } \\
1 \text { year } \\
\text { } 2 \text { years }\end{array}$ \\
\hline
\end{tabular}

BMI, body mass index.

It also collected information about the respondent's sociodemographic characteristics, health including their current health state (AQoL-8D ${ }^{41}$ ), and self-reported height and weight (which was used to estimate respondent BMI).

\section{Sample}

The DCE was administered between November 2013 and February 2014 as part of an online survey to a target sample of 2000 adults residing in Queensland and South Australia, recruited from an online survey panel. Quotas were used to ensure the sample was representative by age and gender for each State. A target sample of 2000 was chosen to ensure precise estimation of preference parameters while also allowing flexibility in modelling heterogeneity. ${ }^{42}$

\section{Data analysis}

A multinomial logit model (MNL) was used to evaluate preferences across the whole sample. ${ }^{42}$ The model coefficients indicate the relative importance of each attribute level in explaining respondent choice. While the main focus of this paper is on the average preferences (based on the MNL model) of the sample, the extent to which preferences differed across respondent subgroups was explored in a online supplementary analysis using a latent class model. ${ }^{43}$ The latent class model can be understood as a process of clustering groups of individuals with similar preferences into a defined number of distinct preference classes. The modelling approach is detailed in the online supplementary appendix.

To develop a prioritisation system based on the preferences of the public that could be used to prioritise individuals for bariatric surgery, 'priority weights' were derived based on the MNL model coefficients, to indicate the relative importance of the different criteria. This was achieved by estimating the marginal rate of substitution between each prioritisation criterion and effectiveness (ie, chance of maintaining weight loss). ${ }^{39}$ The marginal rate of substitution (and therefore priority weight) for each criterion was estimated by dividing the marginal utility for that criterion level by the marginal utility for effectiveness. For example, the weight for prioritising an individual with 'very severe obesity' rather than 'obesity' is equal to the difference between the coefficients from the MNL model between these two attribute levels, divided by the coefficient for a one percentage increase in the chance of maintaining weight loss (ie, priority weight $=\left(\begin{array}{lll}0.28751-(-0.30626) & )\end{array}\right)$ $0.01530)=38.80850$; from results presented in tables 3 and 4; calculations performed prior to rounding of decimal places). This represents the amount of effectiveness that respondents were willing to trade in order to prioritise an individual who met other desirable criteria that were considered to be relevant. Importantly, this approach ensures the priority weights are presented on an interval scale; thus, the weights can be summed for any individual patient requiring surgery in order to rank patients. We illustrate how the priority weights may be used in practice, using three hypothetical patients. 
The following two people both need surgical management for their obesity. Surgery is likely to be the only way to reduce their body weight and their health risks. Both people meet the hospital's clinical criteria for surgery, and the surgery has been recommended by their doctors.

However, demand for the surgery is very high, and only one person can have their surgery now. The other person will have to wait at least another 12 months for surgerv. Who should have their surgerv now?

\begin{tabular}{|c|c|c|}
\hline & Person A & Person B \\
\hline Current level of obesity & $\begin{array}{l}\text { Very Severe Obesity } \\
\text { (BMl greater than } 50 \mathrm{~kg} / \mathrm{m}^{2} \text { ) }\end{array}$ & $\begin{array}{l}\text { Obesity } \\
\text { (BMI } 30 \text { to less than } 40 \mathrm{~kg} / \mathrm{m}^{2} \text { ) }\end{array}$ \\
\hline Obesity-related conditions & $\begin{array}{l}\text { Is at risk of developing obesity- } \\
\text { related conditions }\end{array}$ & $\begin{array}{l}\text { Already has obesity-related } \\
\text { conditions }\end{array}$ \\
\hline $\begin{array}{l}\text { Age of person needing } \\
\text { surgery }\end{array}$ & 50 years & 20 years \\
\hline Family history & $\begin{array}{l}\text { At least one parent or sibling is } \\
\text { obese, has had weight issues } \\
\text { since childhood }\end{array}$ & No family history of obesity \\
\hline $\begin{array}{l}\text { Chance of maintaining a } \\
\text { substantial reduction in } \\
\text { excess weight }\end{array}$ & $30 \%$ & $30 \%$ \\
\hline $\begin{array}{l}\text { Has shown commitment } \\
\text { by responding to } \\
\text { prescribed lifestyle } \\
\text { intervention }\end{array}$ & $\begin{array}{l}\text { Has maintained a healthy } \\
\text { lifestyle plan for several months, } \\
\text { resulting in some weight loss, } \\
\text { however is still in need of } \\
\text { surgery }\end{array}$ & $\begin{array}{l}\text { Has maintained a healthy } \\
\text { lifestyle plan for several months, } \\
\text { resulting in some weight loss, } \\
\text { however is still in need of } \\
\text { surgery }\end{array}$ \\
\hline $\begin{array}{l}\text { Time already spent on } \\
\text { surgery waiting list }\end{array}$ & 6 months & 2 years \\
\hline $\begin{array}{l}\text { Who should have their } \\
\text { surgery now? }\end{array}$ & Person A & Person B \\
\hline
\end{tabular}

Figure 1 Example choice set.

\section{RESULTS}

\section{Respondent characteristics}

A total of 4632 individuals accessed the survey link; of these, 2473 met the eligibility criteria related to age and Australian State and started the survey. The survey was completed by 1994 adults. The characteristics of respondents are given in table 2 . The sample had a mean age of 46.6 years (range 18-88 years), $52.1 \%$ were female, $60 \%$ had a $\mathrm{BMI} \geq 25$ (indicating they were overweight or obese) and $7.1 \%$ reported previous experience with weight management surgery for themselves or a family member. Compared to adults in Australia, the sample were similar in gender, age, indigenous identity, BMI and private health insurance status. On average, the sample had a slightly lower education level, were less likely to be employed, had a lower household income and lower health status than the general population.

\section{Choice responses}

A total of 35892 choice observations were available for analysis in the preference model (18 choices from each of 1994 respondents). The majority $(72.5 \%)$ of respondents provided a consistent response to the repeat choice set. Exclusion of inconsistent respondents made no notable impact on the findings (in terms of significance and rank of the model parameters; data not presented). Therefore, all respondents were included for the analyses. ${ }^{44}$ Most $(64.3 \%)$ respondents reported that they found the survey to be only slightly difficult or not difficult at all.

\section{Priority criteria}

The MNL raw coefficients are presented in table 3 and the prioritisation criteria considered to be important for the public are presented in table 4 and graphically in figure 2. On average, there was a strong preference to prioritise those who had shown commitment to lifestyle change before surgery (weight $79.81,95 \%$ CI 75.79 to $83.88)$. There was also a significant preference to prioritise very severely obese individuals $\left(\mathrm{BMI} \geq 50 \mathrm{~kg} / \mathrm{m}^{2}\right)$ over obese individuals $\left(\mathrm{BMI} \geq 30 \mathrm{~kg} / \mathrm{m}^{2}\right)$. However, this criterion (weight $38.81,95 \%$ CI 36.41 to 41.23 ) was considered to be only half as important as prioritising those who had shown lifestyle commitment. The preference to treat severe obesity $\left(\mathrm{BMI} \geq 40 \mathrm{~kg} / \mathrm{m}^{2}\right)$ over obesity $\left(\mathrm{BMI} \geq 30 \mathrm{~kg} / \mathrm{m}^{2}\right)$ was less strong. Respondents also wanted to prioritise those who already have obesity-related comorbidity, with a family history of obesity, with a greater chance of maintaining weight loss, or who had spent a longer time on the wait list.

There was little inclination to prioritise by age. A small weight was assigned on average to treating a 50-year-old (3.62; $95 \%$ CI 1.30 to 5.93 ) rather than a 20-year old. The priority weight assigned to treating a 35-year old (3.84; $95 \%$ CI -0.31 to 8.00$)$ was greater than for a 50-year-old, but not significantly different to that for a 50 or 20-year old. Given the small and non-linear weights given to prioritising by age, we would not recommend including age as a prioritisation criterion in the development of any policy.

The estimated prioritisation criteria from the public perspective could be adopted into decision-making. A 'referent case', an individual who is obese (BMI $\geq 30$ but $<40 \mathrm{~kg} / \mathrm{m}^{2}$ ), is at risk of comorbid conditions rather than having developed them, has no family history of obesity, has not maintained a healthy lifestyle, has spent a maximum of 6 months on the waiting list, and is assumed to have a $30 \%$ chance of maintaining a substantial (at least 50\%) reduction in excess weight, scores zero points. Other patients in need of surgery could be prioritised relative to this benchmark 'referent case'. Table 5 indicates the priority weights given by the public sample to three hypothetical patients; if managed according to public preferences, priority would be allocated to the patient with the most points.

While the MNL model provides the results of the average respondent from a public sample that reflects the age and gender distribution of the Australian population and therefore provides the relevant weights from a policy perspective, four sociodemographic characteristics (BMI, history of weight loss surgery, AQoL utility score and education level) were significantly associated with membership of a particular preference class in the latent class model $(\mathrm{p} \leq 0.05$; see online supplementary appendix). Notably, respondents who were not overweight or obese, who had no experience of weight loss 
Table 2 Respondent characteristics

\begin{tabular}{|c|c|c|c|c|}
\hline \multicolumn{2}{|l|}{ Characteristic } & \multirow{2}{*}{$\begin{array}{l}\text { Number } \\
1038\end{array}$} & \multirow{2}{*}{$\begin{array}{l}\begin{array}{l}\text { Per cent } \\
(n=1994)^{*}\end{array} \\
52.1\end{array}$} & \multirow{2}{*}{$\begin{array}{l}\text { Australiat } \\
50.2 \%\end{array}$} \\
\hline Gender & Female & & & \\
\hline \multirow[t]{2}{*}{ Age } & Mean (SD) & $46.6(16.5)$ & & \\
\hline & $\geq 50$ years & 849 & 42.60 & $41.5 \%(\geq 15$-year $)$ \\
\hline \multirow[t]{2}{*}{ State } & Qld & 1484 & 74.40 & \\
\hline & SA & 510 & 25.60 & \\
\hline Indigenous & Yes & 50 & 2.50 & $2.5 \%$ \\
\hline Born in Australiał & Yes & 1472 & 73.80 & $72.3 \%$ \\
\hline Main language spoken at home & English & 1875 & 94.00 & \\
\hline Education (highest) & Certificate, Diploma or degree & 892 & 44.70 & $59 \%$ (25-64 year) \\
\hline Employment & Part or full time & 1075 & 53.90 & $\begin{array}{l}60.5 \% \text { ( } \geq 15 \text {-year } \\
\text { civilian population) }\end{array}$ \\
\hline Worked in health system & Yes (during past 10 years) & 227 & 11.40 & \\
\hline Income (annual household) $\ddagger$ & >AU\$100 000 & 374 & 21.80 & $35.1 \%(>A \cup \$ 104400)$ \\
\hline $\begin{array}{l}\text { Private health insurance } \\
\text { Health }\end{array}$ & Hospital cover & 945 & 47.40 & $47 \%$ \\
\hline \multirow[t]{2}{*}{ AQoL-8D health state utility } & Mean (SD) & $0.69(0.21)$ & & Mean 0.86 \\
\hline & $\geq 0.8$ & 750 & 37.84 & \\
\hline BMI & $\geq 25$ & 1171 & 60.10 & $61.4 \%$ \\
\hline Perceived weight $\ddagger$ & Overweight or obese & 1052 & 53.50 & \\
\hline \multicolumn{5}{|l|}{ Health service } \\
\hline Hospital admissions & $\geq 1$ in past 12 months & 399 & 20.01 & $13.2 \%$ \\
\hline GP visits & $\geq 4$ in past 12 months & 679 & 34.10 & $31.9 \%$ \\
\hline Previous weight management surgery & For self or close family member & 141 & 7.10 & \\
\hline \multicolumn{5}{|c|}{$\begin{array}{l}\text { *Valid per cent for AQoL-8D health state utility (12 missing responses); Income (277 missing or prefer not to say); BMI (calculated from height } \\
\text { and weight with } 46 \text { missing or prefer not to say); Perceived weight ( } 29 \text { missing or prefer not to say). } \\
\text { †Source for Australian demographic norms: Australian Bureau of Statistics (ABS) Catalogue 31010DO001_201403 Australian Demographic } \\
\text { Statistics, Mar } 2014 \text { (gender, age); ABS Catalogue 2076.0 Census } 2011 \text { (Indigenous status); ABS Catalogue } 3412.0 \text { Migration, Australia, } \\
2012-2013 \text { (country of birth); ABS Catalogue } 4102.0 \text { Australian social trends 2007: Qualification of Australians (education); ABS Catalogue } \\
6202.0 \text { Labour Force Australia Oct } 2014 \text { (employment); ABS R Catalogue } 6523.0 \text { Household Income and Income Distribution, Australia, } \\
2011-2012 \text { (income); ABS Catalogue } 4364.0 \text { National Health Survey 2004-2005 (private health insurance); AQoL website http://www.aqol. } \\
\text { com.au/index.php/norms (AQoL-8D); AlHW 20107 (BMI); ABS Catalogue 4839.0.55.001 Health Services: Patient Experiences in Australia, } \\
2009 \text { (hospital admissions and G.P. services). } \\
\text { Ilncome, born in Australia and perceived weight were not entered into the LC model, since they displayed correlations above } 0.3 \text { with other } \\
\text { included variables. } \\
\text { BMI, body mass index; GP, general practitioner. }\end{array}$} \\
\hline
\end{tabular}

Table 3 MNL model parameters

\begin{tabular}{|c|c|c|c|c|c|}
\hline Attribute & Level & Coefficient & p Value & Lower $95 \%$ Cl & Upper $95 \% \mathrm{Cl}$ \\
\hline \multirow[t]{3}{*}{ Level of obesity } & Obesity & -0.306 & Ref & & \\
\hline & Severe obesity & * 0.019 & 0.094 & -0.003 & 0.041 \\
\hline & Very severe obesity & $* \star * 0.288$ & $\leq 0.001$ & 0.266 & 0.309 \\
\hline \multirow[t]{2}{*}{ Obesity-related conditions } & At risk of comorbidity & -0.205 & $\overline{\text { Ref }}$ & & \\
\hline & Already has comorbidity & $* * * 0.205$ & $\leq 0.001$ & 0.191 & 0.219 \\
\hline \multirow[t]{3}{*}{ Age of person } & 20 years & -0.038 & Ref & & \\
\hline & 35 years & 0.021 & 0.519 & -0.042 & 0.084 \\
\hline & 50 years & 0.017 & 0.341 & -0.018 & 0.053 \\
\hline \multirow[t]{2}{*}{ Family history } & No family history & -0.082 & Ref & & \\
\hline & Family history & 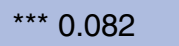 & $\leq 0.001$ & 0.070 & 0.094 \\
\hline Chance of maintaining weight loss & per $\%$ & $* * * 0.015$ & $\leq 0.001$ & 0.014 & 0.016 \\
\hline \multirow[t]{2}{*}{ Commitment } & Not maintained health lifestyle & -0.611 & Ref & & \\
\hline & Maintained healthy lifestyle & $* * * 0.611$ & $\leq 0.001$ & 0.589 & 0.632 \\
\hline Time on wait list & per month & *** 0.031 & $\leq 0.001$ & 0.029 & 0.033 \\
\hline \multicolumn{6}{|c|}{$\begin{array}{l}\text { Ref: Referent level for the model specified with fixed parameter (given effects coding parameter for referent is equal to the negative sum of } \\
\text { the parameters for the other levels for the attribute. }{ }^{63} \text { ). } \\
\text { ***,** } \text { : Significance at } 1 \%, 5 \%, 10 \% \text { level. }\end{array}$} \\
\hline
\end{tabular}


Table 4 Priority weights (based on marginal rates of substitution for MNL model)

\begin{tabular}{|c|c|c|}
\hline Attribute & Level* $^{*}$ & Priority weight (ie, MRS chance in \%)t \\
\hline \multirow{2}{*}{ Level of obesity } & Severe obesity & $21.24(19.46$ to 23.04$)$ \\
\hline & Very severe obesity & 38.81 (36.41 to 41.23$)$ \\
\hline Obesity-related conditions & Already has comorbidity & 26.80 (25.24 to 28.37$)$ \\
\hline \multirow[t]{2}{*}{ Age of person } & Age 35 years & $3.84(-0.31$ to 8.00$)$ \\
\hline & Age 50 years & 3.62 (1.30 to 5.93$)$ \\
\hline Family history & Family history & 10.66 (9.75 to 11.58$)$ \\
\hline Commitment & Maintained healthy lifestyle & 79.81 (75.79 to 83.88$)$ \\
\hline Chance maintain weight loss & Per $\%$ above $30 \%$ & 1.00 (fixed weight) \\
\hline Time on wait list & Per month above 6 months & 2.03 (1.89 to 2.16$)$ \\
\hline
\end{tabular}

surgery, or with better overall health were more likely to belong to a preference class for whom lifestyle commitment was considered to be particularly important. Respondents who were not overweight or obese or who had attained a lower education level were more likely to belong to a class for whom lifestyle commitment was considered to be unimportant. Finally, respondents who were overweight or obese were more likely to belong to a class who considered age should be a prioritisation criterion; though, some prioritised 20-year-olds and some prioritised 50-year-olds. Therefore, individuals differing on these characteristics (BMI, history of weight loss surgery, AQoL utility score and education level) may systematically allocate different priorities across patients requiring surgery than the general public.

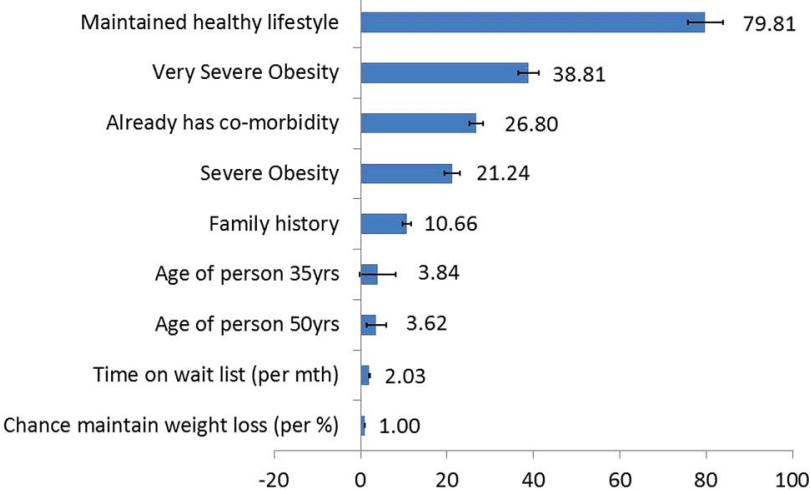

Figure 2 Priority weights for surgery according to criteria (from multinomial logit model model).

Footnote to figure 2: Priority weights are relative to a score of zero for an individual who has obesity, is at risk of comorbid conditions rather than having developed them, has no family history, has not maintained a healthy lifestyle, has spent 6 months on the waiting list, and has a $30 \%$ chance of maintaining a substantial (at least $50 \%$ ) reduction in excess weight. Priority points for time on wait list are per each month over 6 months and for change of maintaining weight loss are for each \% over $30 \%$.

\section{DISCUSSION}

This is the first study to derive preferences of the public that could be used to prioritise elective surgery in the contentious policy area of bariatric surgery, where current demand strongly exceeds the health system's willingness and capacity to supply. The public clearly consider a demonstrated commitment to establishing and maintaining a healthy lifestyle to be the most important prioritisation criterion. Severity of obesity at baseline, the existence of comorbidities and the likely sustained effectiveness of the intervention were all considered to be important, and consistently so, across all preference subgroups. Prioritising surgery for those with a family history of obesity was relevant for the sample overall, but to a lesser extent than the other criteria. Time on the waiting list was also important for the sample overall. The priority weights developed in this study according to a rigorous and systematic methodology can be used to assign priority for access to individuals who may benefit from bariatric surgery. Although this study was undertaken in Australia, it has relevance for other countries, especially relatively high-income countries with well-developed public health systems.

The indicated importance of these criteria, particularly a desire to prioritise the most severely obese and those with comorbidities, are largely consistent with previous studies that suggest public preferences in other health priority setting contexts would prioritise those who are most severely affected by the condition being treated. ${ }^{38}$ They are also largely consistent with existing obesity guidelines, which recommend the use of BMI and/or comorbidities as criteria for surgery. ${ }^{4}{ }^{6}$ However, the strong preference to prioritise those who have shown a prior commitment to changing their lifestyle in support of weight loss, which was by far the most important criterion in this study, is somewhat of an exception. In general, the importance of lifestyle or personal responsibility for illness (when previously explored in preference studies) suggest these may be relevant to the public, but they have generally been found to be of 
Table 5 Illustrative priority for three hypothetical patients, compared to a 'referent case'

\begin{tabular}{|c|c|c|c|c|}
\hline & 'Referent case' & Patient 1 & Patient 2 & Patient 3 \\
\hline \multirow[t]{2}{*}{ Commitment } & No & No & No & Yes \\
\hline & 0 points & 0 points & 0 points & 79.81 points \\
\hline \multirow[t]{3}{*}{ Level of obesity } & Obese (BMI 30 to & Severe (BMI & Very severe (BMI & Very severe (BMl \\
\hline & $\left.<40 \mathrm{~kg} / \mathrm{m}^{2}\right)$ & $\left.\geq 40 \mathrm{~kg} / \mathrm{m}^{2}\right)$ & $\left.\geq 50 \mathrm{~kg} / \mathrm{m}^{2}\right)$ & $\geq 50 \mathrm{~kg} / \mathrm{m}^{2}$ ) \\
\hline & 0 points & 21.24 points & 38.81 points & 38.81 points \\
\hline \multirow{4}{*}{$\begin{array}{l}\text { Obesity-related conditions } \\
\text { (comorbidity) } \\
\text { Family history }\end{array}$} & No & No & Yes & Yes \\
\hline & 0 points & 0 points & 26.80 points & 26.80 points \\
\hline & No & No & No & No \\
\hline & 0 points & 0 points & 0 points & 0 points \\
\hline \multirow[t]{2}{*}{ Time on wait list } & $\leq 6$ months & 12 months & 12 months $(6 \times 2.03)$ & 6 months \\
\hline & 0 points & (6×2.03) points & points & 0 points \\
\hline Assumed chance maintain substantial & $30 \%$ & $30 \%$ & $40 \%$ & $50 \%$ \\
\hline reduction in weight loss & 0 points & 0 points & $(10 \times 1.00)$ points & $(20 \times 1.00)$ points \\
\hline Total priority points & 0 points & 33.42 points & 87.79 points & 165.42 points \\
\hline
\end{tabular}

BMI, body mass index.

relatively minor importance compared to other prioritisation criteria, and may well be context dependent. ${ }^{38} 45$ However, personal responsibility has been found to be a strong predictor of public opinion around the allocation of donor livers, where public preferences have favoured allocation to naturally occurring rather than alcoholic liver disease. ${ }^{46}$ The public have also supported rationing treatment for patients with 'unhealthy lifestyles' in opinion polls. ${ }^{47}$ Furthermore, the perceived importance of lifestyle commitment is also rational, in that weight loss maintenance after most forms of surgery requires continued lifestyle change that is, there will be regression in any weight loss if an appropriate diet and physical activity regimen are not adopted. Nevertheless, we are not aware of any previous preference study that has attempted to quantify priorities for bariatric surgery from a public perspective, and as such this applied study makes an important contribution to develop priority weights that could be assigned to encapsulate the general public's preferences in prioritising access to bariatric surgery for adults.

Age as a criterion for access to care is a contentious issue, and has been found to be of varying importance for the public in previous studies. ${ }^{38} 48-56$ Age was not important for most respondents to this study in the context of prioritising bariatric surgery. This is consistent for example with the deliberations of the National Institute for Health and Care Excellence Citizens' Council in the UK, that age should not be considered as a prioritisation criterion (in health technology assessment), unless it is associated with the level of health outcome. $^{57}$ However, variation in preferences was observed across respondents in the latent class model, including for the age criterion (which was important for some classes). Interestingly, the age of the respondent was not found to be associated with preference for prioritising bariatric surgery in the latent class model; suggesting, self-interest does not explain choices for priority setting by age. The supplementary finding of variation of preferences across respondents highlights the need to ensure a relevant and representative sample is achieved when canvassing preferences to inform policy. It seems likely that the differing opinions around prioritising by age found in previous studies may be explained at least in part by the distinct preference samples involved. ${ }^{38}$ Our results suggest that, at least in the context of prioritising for bariatric surgery in Australia, recipient age should not be a prioritisation criterion (beyond any capacity it has to impact on outcomes). Whether this also applies in other contexts and countries is an empirical question requiring further investigation.

The choice tasks given to respondents in this study were of necessity somewhat simplified to enable their administration to laypersons in a survey format. However, the clinical decision-making context around the appropriateness of bariatric surgery for specific individuals and who would benefit most, is complex. For example, the benefits of surgery may extend beyond weight loss and include metabolic outcomes, leading to the emergence of 'metabolic surgery' which has differing therapeutic goals and a lower BMI criterion threshold, with some effects occurring independent of weight loss. ${ }^{58} 59$ Thus, the potential criteria used in this DCE may not be the only criteria of clinical relevance for selection of individuals for surgery. The inadequacy of BMI as a primary clinical criterion for selection for surgery and potential of other clinical criteria to augment selection has been highlighted. ${ }^{58}$ Further, those with a higher BMI and comorbidities such as diabetes, obstructive sleep apnoea and cardiac disease, may be at greater risk of adverse events from surgery. ${ }^{58}$ Thus, the optimal selection of candidates for bariatric surgery from a clinical perspective so as to balance the benefits and risks of surgery is not straight forward. Nevertheless, despite these potential limitations, the current study focused on prioritising individuals for surgery assuming 
surgery was considered to be clinically appropriate. Respondents were instructed in the survey to imagine that each of the potential surgery recipients had been clinically assessed to be in equal need of surgery to manage their obesity. Thus, any 'real world' clinical consideration around the benefit of surgery was held constant in each hypothetical choice and should not have impacted the hypothetical decisions.

Individuals participating in this study differed in their preferences for the importance of different prioritisation criteria. While respondent age was not observed to affect priority choices, BMI was perhaps unsurprisingly associated with preference class membership, reaffirming the need to give careful consideration to whose preferences are sought to inform priority decisions-the public or individuals with some direct or indirect experience of the condition. ${ }^{31} 336162$ This study takes the normative position that it is the preferences of the public, rather than individuals with a specific condition, that are relevant for informing priority setting decisions. Moreover, for health services funded by taxation of the public, the public are a key stakeholder in how those funds are used. Therefore, the publics' perspective is important for allocating funds to specific services. While this is an accepted approach in health economics in the context of priority setting, ${ }^{38}$ the exploratory latent class analysis in this study suggests that the preferences of an obese population around priorities for bariatric surgery may differ to those of the general public. Although associations between preference and individual characteristics were tested for many sociodemographic characteristics, it is perhaps surprising that only four sociodemographic characteristics were associated with membership of different preference classes at conventional levels of significance in this large sample. It seems possible that class membership, particularly for potentially contentious decisions, might depend more strongly on attitudes and beliefs, cultural differences, and/or individual tastes, all of which are challenging to observe or measure, than on sociodemographic characteristics. However, we can conclude that the representativeness of the sample should be a key methodological consideration for preference studies that seek to inform public policy; and is likely to matter in particular where recipient age or personal responsibility is a criterion under consideration.

Consequently, the main limitation of this study is that we recruited from a panel sample. Although the sample was representative of the Australian public by age and gender, these two characteristics were not found to be significantly associated with preferences and we cannot be sure whether the sample reflects the diversity of the population on a wider range of characteristics that might be associated with preferences-not least because we have been unable to identify what those characteristics are. Although the sample only recruited from two Australian states, these states account for $27.2 \%$ of the Australian population. The sample differed descriptively from the Australian population on a number of characteristics (education level, employment status, household income and health status). Of these, only health status and education level were found to be associated with preference class in secondary latent class analyses (see online supplementary material). Therefore, it is not known to what extent this recruitment approach may have impacted the representativeness of the overall sample preferences. Further research into characteristics beyond sociodemographics that might impact preferences, such as attitudes and beliefs, and the extent to which samples are representative on these less tangible characteristics, is needed. The implementation of the findings may also be limited since application of the priority weights requires an ability to predict the category into which each patient fits for each of the attributes, before their treatment. This may be challenging for the attribute 'chance of maintaining weight loss', since effectiveness is difficult to predict a priori. Nevertheless, estimates of effectiveness are available in the international literature. Alternatively, if distinguishing likely effectiveness between potential patients is considered to be unreliable, this attribute could be excluded from the priority estimates for all potential patients.

To support their capacity to make decisions in the DCE, respondents were provided with some basic information on obesity, its consequences, and its management at the start of the survey. However, obesity and its management is a complex issue and although the pilot study suggested the survey was easy to understand, respondent understanding of the obesity information was not tested in the main survey. Further studies investigating public opinion for prioritising bariatric surgery using a Citizens' Jury, which represents a deliberative approach in which participants are informed and can challenge experts before making recommendations on the issues, are planned as part of the parent study within which this DCE is undertaken. ${ }^{32}$

In conclusion, this study extends our understanding of public preferences for priority setting in the allocation of bariatric surgery in public health services, and derives weights that could be used to prioritise patients for surgery. As such, it provides an exemplar for the growing interest in deriving public preferences to inform prioritisation decisions in healthcare. As preference for prioritisation criteria varied across respondents, achieving a representative sample on relevant characteristics including those that may be difficult to measure is likely to be an important methodological challenge when determining preferences to inform public policy. When setting priorities for the allocation of health services, evidence of public preferences offers a valuable contribution to political debate about the need for prioritisation and the defence of chosen priorities.

Author affiliations

${ }^{1}$ Faculty of Health and Behavioural Sciences, School of Pharmacy, The University of Queensland, St Lucia, Queensland, Australia 
${ }^{2}$ Flinders Health Economics Group, School of Medicine, Flinders University, Adelaide, South Australia, Australia

${ }^{3}$ Centre of National Research on Disability and Rehabilitation, Menzies Health Institute Queensland, Griffith University, Meadowbrook, Queensland, Australia ${ }^{4}$ Urban Research Program, Griffith School of Environment, Griffith University, Southport, Queensland, Australia

${ }^{5}$ Menzies Centre for Health Policy, University of Sydney, New South Wales, Australia

${ }^{6}$ Faculty of Life Sciences and Medicine, King's College London, London, UK ${ }^{7}$ School of Human Services and Social Work, Menzies Health Institute Queensland, Griffith University, Meadowbrook, Queensland, Australia ${ }^{8}$ Centre for Applied Health Economics, Menzies Health Institute Queensland, Griffith University, Meadowbrook, Queensland, Australia

Twitter Follow Paul Burton at @PommiePaulyB

Contributors JAW, JR, EK, PB, AW, PL, PH, RK, PAS conceived and advised on the study. JAW, JR, PAS developed the DCE and guided data collection. JAW led data analysis and interpretation, and drafted the manuscript. All authors contributed to data interpretation, reviewed the draft manuscript, contributed academic content and approved the final version. The authors acknowledge the project team and partners for support with data collection. JAW acts as overall guarantor for this study.

Funding This study was undertaken with the support of funding from an Australian Research Council Linkage Grant (\#LP100200446), and Partner Organisations Queensland Health (Metro South Hospitals and Health Service) Southern Adelaide Local Health Network Inc, and the National Institute for Health and Care Excellence (UK). RK was supported by a grant from the Australian Centre for Health Services Innovation (PostGraduate Scholarship PHD-000432, funded round 1-2013, top up granted 2014). PL is supported by the National Institute for Health Research (NIHR) Collaboration for Leadership in Applied Health Research and Care South London at King's College Hospital NHS Foundation Trust. The researchers were independent from the funders and all authors had full access to all of the data (including statistical reports and tables) in the study and can take responsibility for the integrity of the data and the accuracy of the data analysis. Views expressed by the authors are their own and do not necessarily represent the views of their employing, affiliated or associated organisations.

Competing interests All authors have completed the Unified Competing Interests form at www.icmje.org/coi_disclosure.pdf and declare: all authors had financial support from the Australian Research Council (Linkage Grant \#LP100200446) for the submitted work; RK received financial support from the Australian Centre for Health Services Innovation (PostGraduate Scholarship PHD-000432, funded round 1-2013, top up granted 2014); PL is supported by the National Institute for Health Research (NIHR) Collaboration for Leadership in Applied Health Research and Care South London at King's College Hospital NHS Foundation Trust; no financial relationships with any organisations that might have an interest in the submitted work in the previous 3 years; no other relationships or activities that could appear to have influenced the submitted work. Views expressed by the authors are their own and do not necessarily represent the views of their employing, affiliated or associated organisations.

Ethics approval Ethical approval for this study was granted by Griffith and Flinders' University Human Research Ethics Committees (MED/09/12/HREC; 6088 SBREC). The project was assessed as being low risk from an ethical perspective and informed consent was inferred by completion of the survey.

Provenance and peer review Not commissioned; externally peer reviewed.

Data sharing statement The full data set and statistical code are available on an individual basis (with restrictions on use) from the corresponding author at j.whitty@uq.edu.au. Consent was not obtained but the data are anonymised and risk of identification is low.

Open Access This is an Open Access article distributed in accordance with the Creative Commons Attribution Non Commercial (CC BY-NC 4.0) license, which permits others to distribute, remix, adapt, build upon this work noncommercially, and license their derivative works on different terms, provided the original work is properly cited and the use is non-commercial. See: http:// creativecommons.org/licenses/by-nc/4.0/

\section{REFERENCES}

1. Colquitt JL, Pickett K, Loveman E, et al. Surgery for weight loss in adults. Cochrane Database Syst Rev 2014;(8):CD003641.

2. O'Brien PE, MacDonald L, Anderson M, et al. Long-term outcomes after bariatric surgery: fifteen-year follow-up of adjustable gastric banding and a systematic review of the bariatric surgical literature. Ann Surg 2013;257:87-94.

3. Lukas N, Franklin J, Lee CM, et al. The efficacy of bariatric surgery performed in the public sector for obese patients with comorbid conditions. Med J Aust 2014;201:218-22.

4. National Health and Medical Research Council. Clinical practice guidelines for the management of overweight and obesity in adults, adolescents and children in Australia. Melbourne: National Health and Medical Research Council, 2013. Report Number N57. https:// www.nhmrc.gov.au/guidelines-publications/n57

5. Picot J, Jones J, Colquitt JL, et al. The clinical effectiveness and cost-effectiveness of bariatric (weight loss) surgery for obesity: a systematic review and economic evaluation. Health Technol Assess 2009;13:1-190, 215-357, iii-iv.

6. National Institute for Health and Care Excellence. Obesity: identification, assessment and management of overweight and obesity in children, young people and adults [NICE Guidelines CG189]. National Institute for Health and Care Excellence, 2014.

7. Australian Institute of Health and Welfare. Weight loss surgery in Australia. Canberra: Australian Institute of Health and Welfare, 2010.

8. Korda RJ, Joshy G, Jorm LR, et al. Inequalities in bariatric surgery in Australia: findings from 49,364 obese participants in a prospective cohort study. Med J Aust 2012;197:631-6.

9. Abelson J, Giacomini M, Lehoux P, et al. Bringing 'the public' into health technology assessment and coverage policy decisions: from principles to practice. Health Policy 2007;82:37-50.

10. Menon D, Stafinski T. Role of patient and public participation in health technology assessment and coverage decisions. Expert Rev Pharmacoecon Outcomes Res 2011;11:75-89.

11. Calnan M. Citizens' views on health care. J Manag Med 1995;9:17-23.

12. Mooney $\mathrm{GH}$, Blackwell $\mathrm{SH}$. Whose health service is it anyway? Community values in healthcare. Med J Aust 2004;180:76-8.

13. Tritter JQ, McCallum A. The snakes and ladders of user involvement: moving beyond Arnstein. Health Policy 2006;76:156-68.

14. Arnstein S. A ladder of citizen participation. J Am Inst Planners 1969;35:216-24.

15. Gauvin FP, Abelson J, Giacomini M, et al. "It all depends": conceptualizing public involvement in the context of health technology assessment agencies. Soc Sci Med 2010;70:1518-26.

16. Mullen PM. Public involvement in health care priority setting: an overview of methods for eliciting values. Health Expect 1999;2:222-34.

17. Rowe G, Frewer LJ. A typology of public engagement mechanisms. Sci Technol Human Values 2005;30:251-90.

18. Mitton C, Smith N, Peacock S, et al. Public participation in health care priority setting: a scoping review. Health Policy 2009;91:219-28.

19. Whitty JA. An international survey of the public engagement practices of health technology assessment organizations. Value Health 2013;16:155-63.

20. Street JM, Braunack-Mayer AJ, Facey K, et al. Virtual community consultation? Using the literature and weblogs to link community perspectives and health technology assessment. Health Expect 2008;11:189-200.

21. Daniels N, Sabin J. Setting limits fairly: can we learn to share medical resources? New York: Oxford University Press Inc, 2002.

22. Brouwer WB, Culyer AJ, van Exel NJ, et al. Welfarism vs. extra-welfarism. J Health Econ 2008;27:325-38.

23. Birch S, Donaldson C. Valuing the benefits and costs of health care programmes: where's the 'extra' in extra-welfarism? Soc Sci Med 2003;56:1121-33.

24. Stamuli E. Health outcomes in economic evaluation: who should value health? Br Med Bull 2011;97:197-210

25. Rawlins MD. Pharmacopolitics and deliberative democracy. Clin Med 2005;5:471-5

26. Florin D, Dixon J. Public involvement in health care. BMJ 2004;328:159-61.

27. Mitton CR, McMahon M, Morgan S, et al. Centralized drug review processes: are they fair? Soc Sci Med 2006;63:200-11.

28. Whitty JA, Littlejohns P. Social values and health priority setting in Australia: an analysis applied to the context of health technology assessment. Health Policy 2014:119:127-36.

29. Clark S, Weale A. Social values in health priority setting: a conceptual framework. J Health Organ Manag 2012;26:293-316. 
30. Wiseman V, Mooney G, Berry G, et al. Involving the general public in priority setting: experiences from Australia. Soc Sci Med 2003;56:1001-12.

31. Robinson A, Parkin D. Recognising diversity in public preferences: the use of preference sub-groups in cost-effectiveness analysis. A response to Sculpher and Gafni. Health Econ 2002;11:649-51.

32. Scuffham PA, Ratcliffe J, Kendall E, et al. Engaging the public in healthcare decision-making: quantifying preferences for healthcare through citizens' juries. BMJ Open 2014;4:e005437.

33. Whitty JA, Burton $\mathrm{P}$, Kendall $\mathrm{E}$, et al. Harnessing the potential to quantify public preferences for healthcare priorities through citizens' juries. Int J Health Policy Manag 2014;3:57-62.

34. Ryan M, Farrar S. Using conjoint analysis to elicit preferences for health care. BMJ 2000;320:1530-3.

35. de Bekker-Grob EW, Ryan M, Gerard K. Discrete choice experiments in health economics: a review of the literature. Health Econ 2012;21:145-72.

36. Ubach $\mathrm{C}$, Scott $\mathrm{A}$, French $\mathrm{F}$, et al. What do hospital consultants value about their jobs? A discrete choice experiment. BMJ 2003;326:1432.

37. Sculpher M, Bryan S, Fry P, et al. Patients' preferences for the management of non-metastatic prostate cancer: discrete choice experiment. BMJ 2004;328:382.

38. Whitty JA, Lancsar $\mathrm{E}$, Rixon $\mathrm{K}$, et al. A systematic review of stated preference studies reporting public preferences for healthcare priority setting. Patient 2014;7:365-86.

39. Bridges JF, Hauber AB, Marshall D, et al. Conjoint analysis applications in health-a checklist: a report of the ISPOR Good Research Practices for Conjoint Analysis Task Force. Value Health 2011;14:403-13.

40. Reed Johnson F, Lancsar E, Marshall D, et al. Constructing experimental designs for discrete-choice experiments: report of the ISPOR Conjoint Analysis Experimental Design Good Research PracticesTask Force. Value Health 2013;16:3-13.

41. Richardson J, lezzi A, Khan MA, et al. Validity and reliability of the Assessment of Quality of Life (AQoL)-8D multi-attribute utility instrument. Patient 2014;7:85-96.

42. Hensher DA, Rose JM, Greene WH. Applied choice analysis: a primer. New York: Cambridge University Press, 2005.

43. Whitty JA, Stewart S, Carrington MJ, et al. Patient preferences and willingness-to-pay for a home or clinic based program of chronic heart failure management: findings from the Which? Trial. PLoS ONE 2013;8:e58347.

44. Lancsar E, Louviere J. Deleting 'irrational' responses from discrete choice experiments: a case of investigating or imposing preferences? Health Econ 2006;15:797-811.

45. Neuberger J, Adams D, MacMaster P, et al. Assessing priorities for allocation of donor liver grafts: survey of public and clinicians. BMJ 1998;317:172-5.

46. Ratcliffe J. Public preferences for the allocation of donor liver grafts for transplantation. Health Econ 2000;9:137-48.

47. Smyth C, Coates S. Ration NHS care for alcoholics, smokers and obese, say voters. U.K. The Times (Health News), 1 January 2015.
48. Diederich A, Swait J, Wirsik N. Citizen participation in patient prioritization policy decisions: an empirical and experimental study on patients' characteristics. PLOS ONE 2012;7:e36824.

49. Diederich A, Winkelhage J, Wirsik N. Age as a criterion for setting priorities in health care? A survey of the German public view. PLoS ONE 2011;6:e23930.

50. Lancsar E, Wildman J, Donaldson C, et al. Deriving distributional weights for QALYs through discrete choice experiments. J Health Econ 2011;30:466-78.

51. Dolan $\mathrm{P}$, Tsuchiya $\mathrm{A}$. It is the lifetime that matters: public preferences over maximising health and reducing inequalities in health. J Med Ethics 2012;38:571-3.

52. Eisenberg D, Freed GL, Davis MM, et al. Valuing health at different ages: evidence from a nationally representative survey in the US Appl Health Econ Health Policy 2011;9:149-56.

53. Nord E, Street A, Richardson J, et al. The significance of age and duration of effect in social evaluation of health care. Health Care Anal 1996;4:103-11.

54. Baker R, Bateman I, Donaldson C, et al. Weighting and valuing quality-adjusted life-years using stated preference methods: preliminary results from the Social Value of a QALY Project. Health Technol Assess 2010;14:1-162.

55. Whitty JA, Ratcliffe J, Chen G, et al. Australian public preferences for the funding of new health technologies: a comparison of discrete choice and profile case best-worst scaling methods. Med Decis Making 2014;34:638-54

56. Erdem S, Thompson C. Prioritising health service innovation investments using public preferences: a discrete choice experiment. BMC Health Serv Res 2014;14:360.

57. National Institute for Health and Clinical Excellence. NICE Citizens Council Report on Age. National Institute for Health and Clinical Excellence, 2003.

58. Fruhbeck G. Bariatric and metabolic surgery: a shift in eligibility and success criteria. Nat Rev Endocrinol 2015;11:465-77.

59. Fried M, Yumuk V, Oppert JM, et al. Interdisciplinary European guidelines on metabolic and bariatric surgery. Obes Surg 2014;24:42-55.

60. Gómez-Ambrosi J, Moncada R, Víctor V, et al. Cardiometabolic profile related to body adiposity identifies patients eligible for bariatric surgery more accurately than BMI. Obes Surg 2015;25:1594-603.

61. Sculpher M, Gafni A. Recognizing diversity in public preferences: the use of preference sub-groups in cost-effectiveness analysis. Health Econ 2001;10:317-24.

62. Sculpher M, Gafni A. Recognising diversity in public preferences: the use of preference sub-groups in cost-effectiveness analysis. Author's reply. Health Econ 2002;11:653-4.

63. Bech M, Gyrd-Hansen D. Effects coding in discrete choice experiments. Health Econ 2005;14:1079-83.

64. Daly A, Hess S, de Jong G. Calculating errors for measures derived from choice modelling estimates. Transportation Research Part $B$ 2012;46:333-41. 